\title{
Limited surgical approach for explanting the HeartMate II left ventricular assist device after myocardial recovery
}

\author{
S. Haj-Yahia, MD, E. J. Birks, MD, G. Dreyfus, MD, and A. Khaghani, FRCS, London, United Kingdom
}

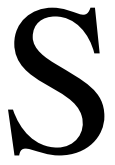

uccessful myocardial recovery in patients with end-stage heart failure after left ventricular assist device (LVAD) support combined with pharmacologic therapy is frequently encountered in our institution. ${ }^{1}$ Minor surgical trauma in explanting ventricular assist devices (VADs) from recovered patients plays an important role in a successful bridge-to-recovery procedure. $^{2,3} \mathrm{We}$ report a minimally invasive technique for explanting the HeartMate II LVAD (ThermoCardiosystems, Inc, Woburn, Mass).

\section{Clinical Summary}

The technique consists of a small (approximately $5 \mathrm{~cm}$ ) left anterolateral thoracotomy through the fifth intercostal space, followed by a small right anterior parasternal thoracotomy (approximately $4 \mathrm{~cm}$ ) through the second intercostal space and a small superior epigastric

From Cardiothoracic Transplantation and Mechanical Circulatory Support, Royal Brompton and Harefield Hospital, National Heart and Lung Institute, Imperial College for Science, Technology and Medicine, London, United Kingdom.

Received for publication Aug 17, 2007; revisions received Oct 5, 2007; accepted for publication Oct 15, 2007.

Address for reprints: Asghar Khaghani, FRCS, Cardiothoracic Transplantation and Mechanical Circulatory Support, Royal Brompton and Harefield Hospital NHS Trust, Hill End Rd, Harefield, Middlesex, London UB9 6JH, United Kingdom (E-mail: S.Haj-Yahia@imperial.ac.uk).

J Thorac Cardiovasc Surg 2008;135:453-4

$0022-5223 / \$ 34.00$

Copyright (C) 2008 by The American Association for Thoracic Surgery doi:10.1016/j.jtcvs.2007.10.012 incision (approximately $5 \mathrm{~cm}$ ) dissecting and exposing the apex, the outflow joints, and the body of the device, respectively (Figure 1). Cardiopulmonary bypass (CPB) is established through arterial cannulation in the LVAD outflow line and femoral vein cannulation for venous return (Figure $1, B$ ). The VAD is switched off, the outflow line is clamped below the CPB arterial cannulation site, and the heart is fibrillated after beginning CPB.

At this stage, the inflow cannula is removed from the left ventricle, the apex is oversewn, and the heart is defibrillated externally or internally. After weaning the patient from CPB support with inotropes and nitric oxide routinely, the CPB cannulae are removed, and the outflow Dacron graft is divided and oversewn proximal to the aorta, leaving a stump of less than $1 \mathrm{~cm}$ (Figure 2, $A$ ). The inflow component of the VAD is dismantled from the main pump, the driveline is divided close to the main device, and then both are removed through the epigastric incision (Figure 2, B). To avoid contamination, the power cable driveline is removed only after the closure of all incisions, leaving the driveline exit site open to drain (Figure 2,B).

Two patients with HeartMate II LVADs implanted for dilated cardiomyopathy received our combination of LVAD and pharmacologic therapy, ${ }^{1}$ resulting in sufficient myocardial recovery to allow explantation of the device by using this limited surgical approach technique. Both were male; ages at explantation were 19 and 42 years, respectively; and the duration of mechanical circulatory support was 156 and 205 days, respectively. The postoperative course was uneventful, with a $100 \%$ survival rate. The mean postoperative ventilation time, intensive care unit length of stay, and hospital stay were 30 hours, 4 days, and 14 days, respectively. The total postoperative blood loss until drains were removed was $467 \mathrm{~mL}$. The number of blood units and amounts of fresh frozen plasma, platelets, and cryoprecipitate administered were $3.5,1.5,1$, and 0 , respectively.
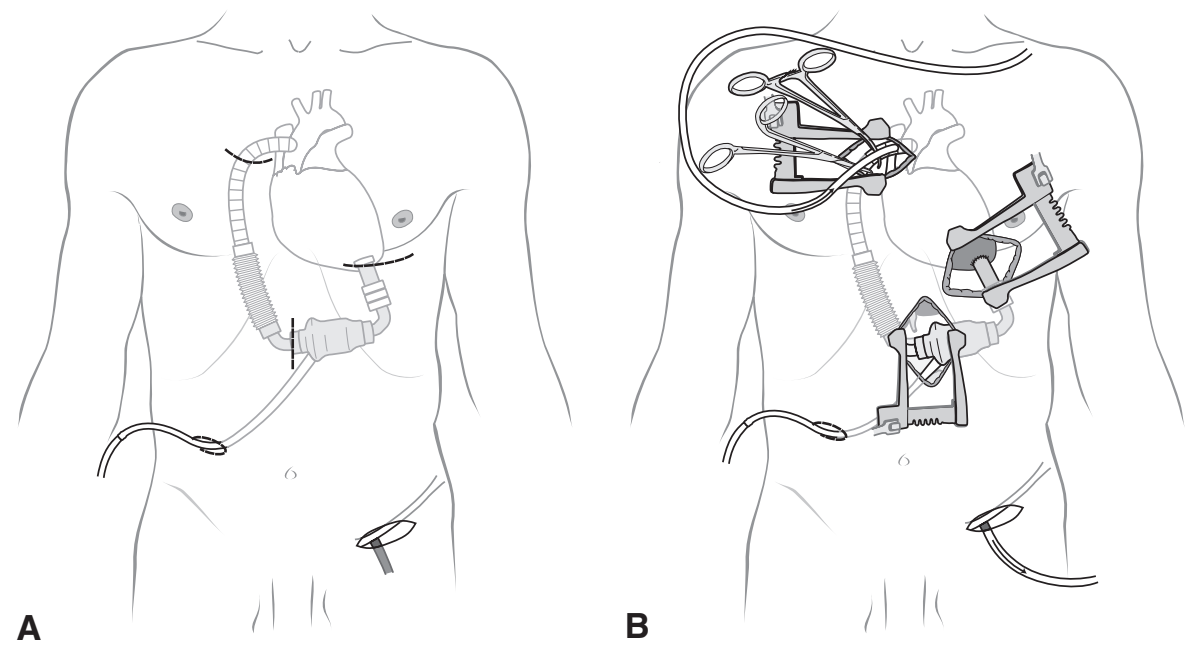

Figure 1. A, Demonstration of the dissection and exposure of the inflow and outflow tubes and pump. B, Establishment of cardiopulmonary bypass through the left ventricular assist device outflow line and femoral venous cannulation for arterial and venous return, respectively. 

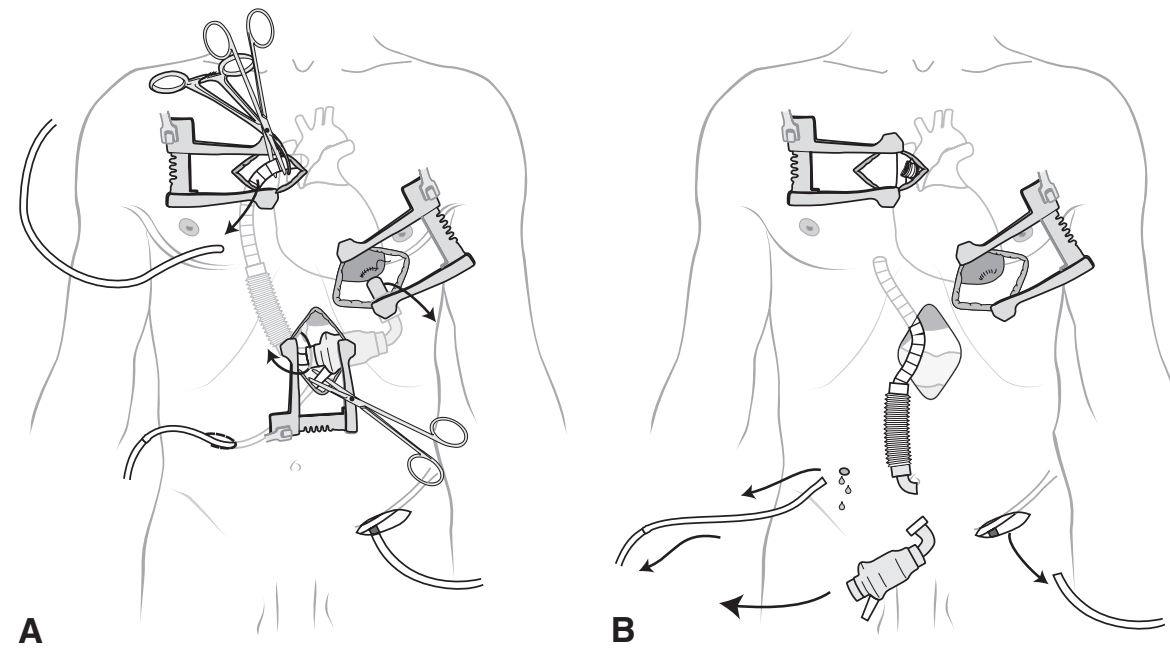

Figure 2. A, Removal of the inflow cannula and oversewing of the apex, followed by dismantling the outflow from the main pump and snipping off the power cable lead close to the pump. B, The outflow Dacron line is divided and oversewn proximal to the aorta. The inflow line is dismantled from the main pump, and both are removed through the epigastric incision. The power cable driveline is removed only after the closure of all incisions, leaving the driveline exit site open to drain.

There was no incidence of wound infection or any other complications.

\section{Discussion}

Removing LVADs after myocardial recovery can be very difficult and challenging because of dense mediastinal adhesions and the risk of surgical trauma during the dissection, which can be very damaging to the recovered heart. Additionally, a full sternotomy and mobilization of the heart can cause excessive bleeding, requiring more blood and blood products, which might affect the pulmonary vascular resistance and subsequently might be detrimental to the right ventricular function.

For that reason, we think that the avoidance of median sternotomy and mobilization of the heart by limiting the surgical approach contributes to the success of the bridge to recovery and has improved our final results. ${ }^{1}$ It also can facilitate the patient's postoperative recovery and mobilization.
The HeartMate II LVAD can be explanted by using a minimally invasive surgical technique. This procedure might play an important role in explant success, maintaining good ventricular function and reducing complications in recovered patients with LVADs.

We thank the Harefield VAD team for their help in data collection and their dedicated care to all patients receiving VADs.

\section{References}

1. Birks EJ, Tansley PD, Hardy J, George RS, Bowles CT, Burke M, et al Left ventricular assist device and drug therapy for the reversal of heart failure. N Engl J Med. 2006;355:1873-84.

2. Haj-Yahia S, Birks EJ, Hardy J, Yacoub MH, Khaghani A. Minimally invasive technique for explantation of right ventricular assist devices. Ann Thorac Surg. 2006;82:1547-8.

3. Tansley P, Yacoub M. Minimally invasive explantation of implantable left ventricular assist devices. J Thorac Cardiovasc Surg. 2002;124:189-91. 